\title{
Prospects for management of ischemia and reperfusion
}

\author{
Perspectivas na terapia da isquemia e reperfusão
}

Carlos Eli Piccinato ${ }^{1 *}$

Despite all of the advances that have been achieved by researchers into the pathophysiology of ischemia and reperfusion (I/R), there is still a great deal to be investigated. Enormous challenges remain in understanding the mechanisms of injury and, clearly, in introducing new treatments. Faced with a patient with acute ischemia of an extremity, the vascular surgeon's greatest concern will always be to achieve successful revascularization, while bearing in mind the risks involved in this procedure in more serious situations. It is very difficult to determine the limit of cell viability, particularly on the basis of clinical examination and this fact is the reason that surgeons tend to favor revascularization in attempts to salvage the ischemic limb.

The first step in managing patients with nontraumatic acute ischemia of a limb is to initiate anticoagulation treatment, generally using heparin. The objective of anticoagulation is to avert thrombus propagation during the interval of time in which the patient is being evaluated, resuscitated and prepared for intervention, whether this be open or endovascular surgery. Although there is significant experimental data indicating that $\mathrm{I} / \mathrm{R}$ has metabolic, inflammatory and thrombotic components that initiate locally in the ischemic extremity before reperfusion, conventional clinical studies have not employed metabolic techniques or anti-inflammatory treatments before reperfusion. Rather, the majority of clinical studies have employed therapeutic agents that have a single specific action, whether inflammatory, metabolic or procoagulatory, despite the evidence proving that multiple components are involved in $\mathrm{I} / \mathrm{R}$.

When the oxygenated blood returns to the tissues during reperfusion, numerous reactive oxygen species (ROS) are generated, in addition to those already triggered by the ischemia. Antioxidant interventions have been extensively investigated with a view to impeding the activity of ROS. Free radical scavengers, including allopurinol, superoxide dismutase, catalase and dimethyl sulfoxide and others, have been investigated and shown to attenuate $\mathrm{I} / \mathrm{R}$ injuries in several animal experiments. However, there are also negative reports. Melatonin is produced by the pineal gland and there is growing recognition of its importance as an ROS scavenger in several different organs and tissues, including skeletal muscle.

Ischemic preconditioning (IPC) is the phenomenon by which brief episodes of ischemia and reperfusion trigger an adaptation mechanism which then protects tissues from sustained ischemic injuries after reperfusion. Observations reported by Murry et al. $(1986)^{1}$ led to a substantial increase in enthusiasm about research into IPC - not only for the myocardium, but also in other organs and tissues. Two phases of the IPC protective effect have been described: there is an early protective effect which appears immediately after IPC stimulation, but which disappears within two hours; and there is a later phase of protection which begins around 12 to 24 hours after IPC and lasts from 2 to 3 days. $^{2}$ The majority of studies in the literature have focused on the early phase of protection. However, it is during the later phase of protection provoked by IPC that the greater part of micro-surgical problems arise.

From a clinical point of view, IPC can be employed for certain types of elective surgery, such as transference of free tissue or composite tissues for allotransplantation, during which ischemia can be controlled by the surgeon. For example, after isolation of the free portion, before sectioning the vascular pedicle, IPC maneuvers can be employed to provide protection against reperfusion injuries. However, the most important question is whether IPC is able to provide good protection for human beings. To date, clinical trials of IPC carried out in the fields of liver, heart and lung surgery have had favorable results. ${ }^{3}$ Another maneuver currently under investigation is ischemic post-conditioning (Post-C or intermittent reperfusion), which consists of three cycles of alternate non-occlusion/re-occlusion applied to the vascular pedicle, after prolonged ischemia. Zhao et al. (2003) ${ }^{4}$ have reported that a single maneuver (consisting of three episodes of 30 seconds alternating between non-occlusion and re-occlusion) applied to the anterior descending coronary artery after 60 minutes of sustained 
ischemia significantly reduced myocardial infarction in dogs. Clinically, Post-C can be used to salvage vascularized or amputated limbs in which ischemia has already taken a place or where the window of opportunity for using IPC has already closed. The maneuver is simple and safe, but it must be applied at the start of reperfusion, since reperfusion injury begins within minutes of the restoration of flow.

Recently, IPC theory has been extended to arrive at the concept of remote ischemic preconditioning (RIPC), which is a technique that consists of provoking brief alternating periods of ischemia and reperfusion in an organ or tissue and which provides protection against reperfusion injury in distant organs or tissues. ${ }^{5}$ Encouraging results have also been described after administration of 4/4 minute cycles applied to the thigh, reducing cardioplegic injuries among 81 adults operated on for valve replacement. ${ }^{6}$ However, there is a lack of publications about the role of RIPC with relation to human skeletal muscle.

Nitrite is an inert oxidative metabolite of nitric oxide (NO) that can be found in circulation at micromolar levels. Recently, studies have shown that intravenous administration of nitrates prior to reperfusion has a significant therapeutic protective effect against $\mathrm{I} / \mathrm{R}$ injuries to the myocardium and to the liver. ${ }^{7}$ Nitric oxide synthase (eNOS) converts L-arginine to L-citrulline in the vascular endothelium, to generate NO, which is widely recognized as a protective factor for vascular homeostasis.

Recently, Henderson et al. (2010) studied hydrogen sulfide, ${ }^{8}$ showing that pre-ischemic delivery of hydrogen sulfide limits $I / R$ injuries to skeletal muscle. Research into the benefits of antioxidants for I/R have also resurfaced. Some studies have shown that vitamin $\mathrm{E}$ has a protective effect, averting I/R injuries to skeletal muscle. ${ }^{9}$ Drugs that act on the endothelium and on vascular reactivity have also been studied. For example, cilostazol and pentoxifylline (employed to manage chronic ischemia) and pravastatin and simvastatin (used to reduce cholesterol) have been shown to attenuate $I / R$ injuries to skeletal muscle.

Some authors have also investigated hyperbaric oxygen therapy $(\mathrm{HBO})$ for treatment of $\mathrm{I} / \mathrm{R}$ injuries. Although the clinical efficacy of HBO has been recognized after small scale clinical trials, the potential mechanism remains uncertain.

Hypothermia is often used to preserve amputated tissues prior to reimplantation. Local hypothermia was shown to be protective when administered during the early phase of reperfusion of skeletal muscle, suggesting a potential clinical strategy for minimizing $\mathrm{I} / \mathrm{R}$ injuries. ${ }^{10}$

Promising results have recently been reported with relation to low-level lasers' ability to protect against $\mathrm{I} / \mathrm{R}$ injuries in skeletal muscle ${ }^{11}$ and in random cutaneous flaps from rats. ${ }^{12}$

In an attempt to avoid reperfusing the ischemic limb with normal blood, it has been suggested that a modified solution should be administered via a simplified perfusion system (a hyperosmolar, hyperoncotic and hypocalcemic solution enriched with energy substrate and at low pressure) for 30 minutes before allowing normal blood to flow, with the objective of avoiding the local and systemic complications of $\mathrm{I} / \mathrm{R}$ injuries. Promising clinical results have been reported after use of this technique, ${ }^{13}$ but they were not confirmed in a recent multicenter study. ${ }^{14}$

Despite all of the advances reported in animal experiments investigating treatment of $I / R$ of the extremities, to date applications in humans remain fairly restricted because of the lack of research. Notwithstanding, I/R injuries are of interest to surgeons operating in other specialties involving organ transplantation and transfer of free tissues and so studying the phenomenon could have a significant impact on the overall success rates of these procedures. The interventions described above, such as IPC, Post-C and RIPC could be employed during organ or tissue transplantation procedures. These maneuvers are simple, safe and apparently inoffensive, but randomized multicenter studies are still needed to verify their efficacy.

\section{REFERENCES}

1. Murry CE, Jennings RB, Reimer KA. Preconditioning with ischemia a delay of lethal cell injury in ischemic myocardium. Circulation. 1986;74(5):1124-36. http://dx.doi.org/10.1161/01.CIR.74.5.1124. PMid:3769170

2. Kuzuya T, Hoshida S, Yamashita N, et al. Delayed effects of sublethal ischemia on the acquisition of tolerance to ischemia. Circ Res. 1993;72(6):1293-9. http://dx.doi.org/10.1161/01. RES.72.6.1293. PMid:8495557

3. Jenkins DP, Pugsley WB, Alkhulaifi AM, Kemp M, Hooper J, Yellon DM. Ischaemic preconditioning reduces troponin $T$ release in patients undergoing coronary artery bypass surgery. Heart. 1997;77(4):314-8. PMid:9155608.

4. Zhao ZQ, Corvera JS, Halkos ME, et al. Inhibition of myocardia injury by ischemic postconditioning during reperfusion: comparison with ischemic preconditioning. Am J Physiol Heart Circ Physiol. 2003;285(2):H579-88. PMid:12860564.

5. Przyklenk K, Bauer B, Ovize M, Kloner RA, Whittaker P. Regional ischemic 'preconditioning' protects remote virgin myocardium from subsequent sustained coronary occlusion. Circulation. 1993;87(3):893-9. http://dx.doi.org/10.1161/01.CIR.87.3.893. PMid:7680290 
6. Li L, Luo W, Huang L, et al. Remote perconditioning reduces myocardial injury in adult valve replacement: a randomized controlled trial. J Surg Res. 2010;164(1):e21-6. http://dx.doi. org/10.1016/j.jss.2010.06.016. PMid:20850778

7. Gonzalez FM, Shiva S, Vincent PS, et al. Nitrite anion provides potent cytoprotective and antiapoptotic effects as adjunctive therapy to reperfusion for acute myocardial infarction. Circulation. 2008;117(23):2986-94. http://dx.doi.org/10.1161/ CIRCULATIONAHA.107.748814. PMid:18519850

8. Henderson PW, Singh SP, Weinstein AL, et al. Therapeutic metabolic inhibition: hydrogen sulfide significantly mitigates skeletal muscle ischemia reperfusion injury in vitro and in vivo. Plast Reconstr Surg. 2010;126(6):1890-8. http://dx.doi. org/10.1097/PRS.0b013e3181f446bc. PMid:21124129

9. Piccinato $C E$, De Domenico A Jr, Jordão AA, Vannuchi A. Skeletal muscle ischemia and reperfusion increase lipid peroxidation in rats. Acta Cir Bras. 2004;19(5):578-81. http://dx.doi.org/10.1590/ S0102-86502004000500018.

10. Mowlavi A, Neumeister MW, Wilhelmi B), Song YH, Suchy H, Russell RC. Local hypothermia during early reperfusion protects skeletal muscle from ischemia-reperfusion injury. Plast Reconstr Surg. 2003;111(1):242-50. http://dx.doi.org/10.1097/00006534200301000-00041. PMid:12496585

11. Avni D, Levkovitz S, Maltz L, Oron U. Protection of skeletal muscles from ischemic injury: low-level laser therapy increases antioxidant activity. Photomed Laser Surg. 2005;23(3):273-7. http://dx.doi. org/10.1089/pho.2005.23.273. PMid:15954814

12. Prado R, Neves L, Marcolino A, et al. Effect of low-level laser therapy on malondialdehyde concentration in random cutaneous flap viability. Photomed Laser Surg. 2010;28(3):379-84. http:// dx.doi.org/10.1089/pho.2009.2535. PMid:19877823

13. Beyersdorf $F$, Matheis $G$, Krüger $S$, et al. Avoiding reperfusion injury after limb revascularization: experimental observations and recommendations for clinical application. J Vasc Surg. 1989;9(6):757-66. http://dx.doi.org/10.1016/0741-5214(89)900815. PMid: 2657120

14. Heilmann C, Schmoor C, Siepe M, et al. Controlled reperfusion versus conventional treatment of the acutely ischemic limb: results of a randomized, open-label, multicenter trial. Circ Cardiovasc Interv. 2013;6(4):417-27. http://dx.doi.org/10.1161/ CIRCINTERVENTIONS.112.000371. PMid:23881815

${ }^{*}$ Correspondence Av. Bandeirantes, $s / n$, Monte Alegre CEP 14048-900 - Ribeirão Preto (SP), Brazi E-mail: cepiccin@fmrp.usp.br

Author information CEP is a full professor and head of the Division of Vascular and Endovascular Surgery at FMRP-USP, São Paulo, Brazil. 